\title{
ENSAIOS DE MIGRAÇÃO DE CLORETOS EM ESTADO ESTACIONÁRIO PARA AVALIAÇÃO DE SISTEMAS DE PROTEÇÃO DE SUPERFÍCIE
}

\section{Steady-state chloride migration testing to evaluate the treatment of surface concrete}

\author{
Marcelo Henrique Faria de Medeiros ${ }^{1}$, Lígia Vitória Real ${ }^{2}$, Karoline Richter ${ }^{3}$, \\ Washington Batista Souza ${ }^{4}$, Nayara Soares Klein ${ }^{5}$
}

Recebido em 07 de novembro de 2013; recebido para revisão em 10 de novembro de 2013; aceito em 03 de fevereiro de 2014; disponível on-line em 29 de maio de 2014.

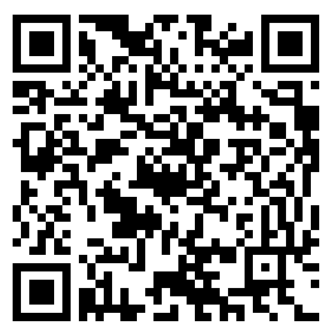

PALAVRAS CHAVE:

Concreto armado;

Proteção de superfície;

Difusão de cloretos;

Estado estacionário.

RESUMO: O concreto é um dos materiais mais utilizados na construção civil, seja para levantar edifícios, seja para erguer obras de arte. Muito do sucesso dessa combinação justifica-se pelo fato de as armações utilizadas para reforço não demandarem, em tese, tratamentos contra corrosão, devido à elevada alcalinidade do concreto. $\mathrm{Na}$ prática, quando há vulnerabilidades no sistema (falhas na execução, exposição a ambientes marinhos), as estruturas podem apresentar problemas. Sob a ação do tempo e do uso, são necessárias manutenções e proteções para manter o estado de conservação do concreto armado. Existem disponíveis no mercado diversos produtos de proteção de superfície para concreto, enquadrados em três categorias: hidrofugantes de superfície, formadores de película e bloqueadores de poros. Este artigo analisou a eficiência desses produtos, comparando o coeficiente de difusão de cloretos obtido através de ensaio de migração destes no estado estacionário, baseado na primeira Lei de Fick. Os ensaios apresentaram que todos os produtos analisados têm capacidade de reduzir o coeficiente de difusão. Os melhores resultados foram obtidos com o uso de formadores de película a base de poliuretano alifático e pelos sistemas duplos de proteção (combinação de hidrofugantes de superfície e formadores de película com base acrílica).

* Contato com o autor:

${ }^{1}$ e-mail : medeiros.ufpr@gmail.com

( M. H. F. de Medeiros )

Prof. Doutor Eng. Civil, Centro Politécnico, CESEC - Universidade Federal do Paraná (UFPR).

2e-mail : ligiavr@gmail.com

( L. V. Real)

Enga. Civil, Mestranda do Centro Politécnico, CESEC - Universidade Federal do Paraná (UFPR).

${ }^{3}$ e-mail : karolrichter@yahoo.com.br

( K. Richter)

Enga. Civil, Mestranda do Centro Politécnico, CESEC - Universidade Federal do Paraná (UFPR).

${ }^{4}$ e-mail : wbsengenharia@gmail.com

(W. B. Souza)

Eng. Civil mestrando do Prog. de Pós-Graduação em Engenharia Civil (PPGEC) - Universidade Tecnológica Federal do Paraná (UTFPR).

.5 e-mail : nayaraklein@ufpr.br

( N. S Klein)

Prof. Doutor Eng. Civil, Centro Politécnico, CESEC - Universidade Federal do Paraná (UFPR).

\section{INTRODUÇÃO}

Qualquer estrutura de concreto com o passar do tempo e sob a ação do uso necessitará passar por serviços de manutenção para assegurar o desempenho adequado de suas funções. Em condições normais, a armadura de aço encontra-se protegida fisicamente por uma barreira, o cobrimento do concreto, que dificulta o ingresso de substâncias que podem dar início ao processo de corrosão da armadura, bem como limita o acesso de água e oxigênio. Entretanto, o sistema contínuo 
dos poros do concreto e a tendência do concreto de formar fissuras superficiais, fazem com que o cobrimento não represente uma barreira perfeita. Desse modo, para garantir o efeito barreira proporcionado pelo cobrimento de concreto, muitas vezes são utilizados revestimentos aplicados sobre as armaduras ou sobre a superfície do concreto. Existe, neste campo, uma grande quantidade de produtos com desempenho distinto e muitas vezes vendidos como similares.

As pesquisas voltadas a esse tema ainda são esparsas, sendo necessário um grande esforço para elaboração do ferramental necessário para estudar a eficiência deste tipo de produto. Dentre as exigências que devem ser atendidas por um sistema de proteção de superfície para concreto armado, destaca-se a baixa permeabilidade a íons cloreto (um dos principais responsáveis pela corrosão de armaduras em estruturas de concreto armado).

Os íons cloreto presentes no concreto podem ser oriundos de diversas fontes. No concreto fresco, por exemplo, podem provir da utilização da água marinha na mistura, de agregados contaminados ou do uso de aditivos aceleradores de pega que contém cloreto de cálcio (amplamente utilizados até meados de 1970). No concreto endurecido, os cloretos podem penetrar na estrutura pelo contato direto com a água do mar, pela presença de maresia, pelos sais de degelo ou em estruturas que armazenem sal, como tanques de salmoura e aquários (BROMMFIELD, 1997).

Os cloretos do ambiente podem entrar na estrutura de concreto através dos mecanismos de penetração de água contaminada e difusão de íons. Para que ocorra a contaminação, os íons precisam estar dissolvidos em água. Como cristal sólido, o cloreto não oferece risco elevado para as estruturas, pois não penetra nos poros. Apesar disso, no estado sólido, o íon pode se depositar por impactação na superfície do concreto e permanecer até que uma chuva o dissolva e o transporte para o interior da estrutura através de absorção capilar ou difusão (HELENE, 1993).
Este artigo visa analisar a eficiência de alguns produtos de proteção de superfície disponíveis no mercado brasileiro, comparando as três categorias comercializadas (hidrofugantes de superfície, formadores de película e bloqueadores de poros) através de ensaio de migração de cloretos em estado estacionário, que representa o mecanismo de difusão de cloretos.

\section{DIFUSÃO DE CLORETOS NO CONCRETO}

A difusão de cloretos consiste no transporte de íons por diferença de concentração em distintas regiões; há um fluxo de íons da região de alta concentração para a de baixa e não há dependência da movimentação da água, mas sim da existência de um eletrólito e de um gradiente de concentração. Segundo Kropp (1995), ainda não existe um ensaio reconhecido em consenso para se obter o coeficiente de difusão de cloretos no concreto. Até o momento a ASTM C1556/2004 é o único método de ensaio normalizado para a determinação do coeficiente de difusão aparente. Desse modo, o concreto pode ser caracterizado por meio do coeficiente de difusão (D), que representa a habilidade do material em permitir o transporte de uma determinada substância em sua massa.

Guimarães (2000) defende que a difusividade de íons cloretos depende do grau de saturação do concreto. O mecanismo de difusão cessa se os caminhos de líquido dos capilares são interrompidos pela secagem. Desse modo, a difusividade máxima ocorre em condições de saturação e decresce continuamente com a redução do teor de umidade. No entanto, segundo Kropp (1995), não existem dados exatos disponíveis que relacionem a difusão com o teor de umidade do concreto. Como o transporte ocorre ao longo dos poros capilares, para haver difusão é preciso que estes estejam totalmente preenchidos com água ou no mínimo conter um alto grau de saturação (GS).

Existem duas maneiras de se determinar o coeficiente de difusão; utilizando o estado de difusão estacionário (não tem a influência da 
fixação de cloretos) ou utilizando ensaios em regime não estacionário, onde a fixação de cloretos influencia no coeficiente de difusão.

\section{SISTEMAS DE PROTEÇÃO}

Os materiais de proteção de superfície para concreto podem ser classificados em três grupos: os formadores de película (formam película sólida através da evaporação por solvente ou por reação química), os bloqueadores de poros ou cristalizantes (penetram nos poros do concreto e reagem com a cal liberada na hidratação do cimento formando um gel de silicato de cálcio ou fluossilicato de cálcio insolúvel) e os hidrofugantes (impedem ou dificultam absorção de água no concreto).

De um modo geral, os formadores de películas requerem um substrato liso, com poros de abertura máxima de 0,1 mm, sendo que a sua grande maioria não é capaz de absorver eventuais fissurações posteriores. Esse sistema de proteção é capaz de reduzir efeitos da carbonatação, lixiviação, permeabilidade e difusividade a sais solúveis, o surgimento de mofo, além de inibir o crescimento de fungos e bactérias (HELENE, 2000).

Os cristalizantes de superfície são materiais do tipo silicatos e fluorsilicatos líquidos e são tradicionalmente utilizados para aumentar a resistência à abrasão de pisos de concreto. Segundo Thompson et al. (1997), a reação de solução de silicato de sódio nos poros do concreto forma um composto que pode ser classificado como C-S-H e ocorre apenas na presença de água. Existem três teorias sobre a ação dos silicatos no sentido de proteger a superfície do concreto. São elas: precipitação de $\mathrm{SiO}_{2}$ nos poros; formação de um gel expansivo, dentro dos poros, similar ao formado na reação álcali silicato; reação dos silicatos com o hidróxido de cálcio presente nos poros formando silicato de cálcio hidratado.

Os hidrofugantes têm como base os silicones, utilizados desde os anos 50 e hoje em sua quarta geração. Entre os procedimentos para proteger superfícies de concreto, as impregnações hidrófugas são as que menos interferem no aspecto estético das edificações. Segundo Jacob \& Hermann (1998), esse sistema é utilizado em superfícies de concreto verticais ou inclinadas, expostas ao intemperismo.

Batista (1998) discorre sobre seu mecanismo de atuação, dizendo que, dependendo do tipo de substrato, os hidrofugantes podem penetrar a profundidades superiores a $10 \mathrm{~mm}$, repelindo a água pela transformação das forças capilares dos poros superficiais, de positivas (sucção) para negativas (repelência). É importante observar que esse tipo de produto reveste internamente os poros, ao invés de cobri-los ou vedá-los como é o caso dos revestimentos formadores de película. Assim, têm a vantagem sobre os produtos formadores de filme de permitir a livre circulação do vapor de água e, com isso, afastar o risco de condensação e formação de bolhas sob o filme. Porém, no caso de materiais a base de cimento Portland, Jacob \& Hermann (1998) apontam para a baixa probabilidade de se obter um tratamento eficaz ao longo do tempo, já que o processo de hidratação não foi concluído no momento do tratamento, podendo-se formar constantemente novas superfícies não umedecidas pelos produtos de impregnação.

Medeiros e Helene (2008) apresentaram que os hidrofugantes são eficazes apenas em condições não saturadas, em que o principal mecanismo de transporte é por sucção capilar. Em condições saturadas ou sob pressão, este tipo de produto não apresenta eficácia satisfatória.

Evidentemente, os hidrofugantes têm a desvantagem de não serem tão eficazes como barreira contínua aos agentes agressivos, quando comparados com os produtos formadores de película. Como alternativa, existem no mercado sistemas de proteção que combinam os dois produtos; base silano/siloxano como primer e metilmetacrilato como verniz de acabamento e proteção, conciliando as vantagens de ambos (HELENE, 1992).

Segundo Medeiros e Helene (2009), a proteção de superfície pode ser um meio eficiente para inibir penetração de cloretos no concreto e, portanto, os sistemas de proteção devem ser 
usados para aumentar a vida útil das estruturas. Em sua pesquisa, os autores apresentaram que um sistema de proteção de alta eficiência pode aumentar a vida útil de uma estrutura de concreto armado em até 7,8 vezes.

\section{PROGRAMA EXPERIMENTAL}

\subsection{CONCRETO DO SUBSTRATO}

Após um estudo de dosagem baseado em Helene e Terzian (1992), o concreto adotado para o substrato padrão foi o traço 1:4,5 (descrito na Tabela 1), por este material possuir fck entre 25 e $30 \mathrm{MPa}$, que está na faixa de resistência mais frequentemente empregada nas obras do estado de São Paulo. Adotou-se a cura em ambiente com
100\% de U.R. durante 91 dias como o período padrão para todos os substratos moldados. É fundamental que a fatia de concreto esteja totalmente saturada no início do ensaio porque a variação do teor de umidade introduz outra variável na determinação do coeficiente de difusão.

\subsection{SISTEMAS DE PROTEÇÃO DE SUPERFíCIE EMPREGADOS}

Foram empregados 13 produtos (descritos na Tabela 2), escolhidos com o intuito de comparar as três categorias de proteção de superfície: hidrofugantes de superfície, formadores de película e bloqueadores de poros. Foi respeitado o consumo de material indicado pelos fabricantes e o tipo de cura adequado para cada situação.

TABELA 1: Proporcionamento de materiais do concreto adotado como o substrato padrão para o desenvolvimento do estudo.

\begin{tabular}{|c|c|c|c|c|c|c|c|c|}
\hline $\begin{array}{l}\text { Proporção } \\
\text { Cimento: } \\
\text { agregados }\end{array}$ & $\begin{array}{c}\text { Teor de } \\
\text { argamassa } \\
\text { (\%) }\end{array}$ & $\begin{array}{c}\text { Cimento } \\
\text { (Kg) }\end{array}$ & $\begin{array}{c}\text { Areia } \\
\text { (kg) }\end{array}$ & $\begin{array}{c}\text { Brita } \\
\text { (kg) }\end{array}$ & $\begin{array}{c}\text { Relação } \\
\text { a/c }\end{array}$ & $\begin{array}{l}\text { Consumo de } \\
\text { cimento } \\
\left(\mathrm{kg} / \mathrm{m}^{3}\right)\end{array}$ & H (\%) & $\begin{array}{c}\text { Resistência à } \\
\text { compressão (MPa) - } \\
28 \text { dias }\end{array}$ \\
\hline Traço 1:4,5 & 51 & 1 & 1,80 & 2,70 & 0,525 & 358 & 9,5 & 32 \\
\hline
\end{tabular}

Nota 1: O cimento empregado no concreto do substrato foi do tipo CPII-E 32, fabricado pela Ciminas.

Nota 2: Relação água/mistura seca.

TABELA 2: Descrição dos sistemas que compõem o estudo.

\begin{tabular}{|c|c|c|c|}
\hline Grupo & $\begin{array}{l}\text { Sistema de } \\
\text { proteção }\end{array}$ & Identificação & Descrição do fabricante \\
\hline $\begin{array}{l}\text { Hidrofugantes } \\
\text { de superfície }\end{array}$ & Simples & Hidrofugante $(\mathrm{A})$ & Hidrofugante silano/siloxano - base água \\
\hline \multirow{7}{*}{$\begin{array}{l}\text { Formadores } \\
\text { de película }\end{array}$} & Simples & Hidrofugante (B) & Hidrofugante silano/siloxano - base solvente \\
\hline & Simples & Hidrofugante (C) & Hidrofugante silano/siloxano - base solvente \\
\hline & Simples & Acrílico (1)-solv. & Verniz acrílico - base solvente \\
\hline & Simples & Acrílico (2)-solv. & Verniz acrílico - base solvente \\
\hline & Simples & Acrílico (3)-água & Verniz acrílico - base água \\
\hline & Simples & $\mathrm{PU}(1)$ & Verniz poliuretano alifático (Bicomponente) \\
\hline & Simples & $\mathrm{PU}(2)$ & Verniz poliuretano alifático (Bicomponente) \\
\hline \multirow{2}{*}{$\begin{array}{l}\text { Sistemas } \\
\text { duplos }\end{array}$} & Duplo & $\begin{array}{l}\text { Hidrofugante }(A)+ \\
\text { Acrílico (1)-solv. }\end{array}$ & $\begin{array}{c}\text { (Hidrofugante silano/siloxano - base água) + (Verniz acrílico } \\
\text { - base solvente) }\end{array}$ \\
\hline & Duplo & $\begin{array}{l}\text { Hidrofugante (B) + } \\
\text { Acrílico (1)-solv. }\end{array}$ & $\begin{array}{c}\text { (Hidrofugante silano/siloxano - base solvente) + (Verniz } \\
\text { acrílico - base solvente) }\end{array}$ \\
\hline \multirow{3}{*}{$\begin{array}{l}\text { Bloqueadores } \\
\text { de poros }\end{array}$} & Simples & Silicato de sódio (20\%) & $\begin{array}{l}\text { Solução aquosa de silicato de sódio com } 20 \% \text { de } \\
\text { concentração }\end{array}$ \\
\hline & Simples & $\begin{array}{c}\text { Tratamento comercial } \\
\text { a base de silicato }\end{array}$ & $\begin{array}{c}\text { Produto a base de silicato de sódio comercializado para } \\
\text { proteção e impermeabilização do concreto }\end{array}$ \\
\hline & Simples & $\begin{array}{c}\text { Silicato de sódio } \\
\text { líquido }\end{array}$ & Silicato de sódio líquido \\
\hline
\end{tabular}




\subsection{ENSAIO DE MIGRAÇÃO DE CLORETOS}

O método de ensaio utilizado para avaliar a migração de cloretos foi baseado na primeira lei de Fick (que define o fluxo de massa como a massa que está em difusão através de uma área por unidade de tempo), relativa a difusão no estado estacionário. 0 procedimento consiste em submeter fatias de $25 \mathrm{~mm}$ de espessura extraídos de corpos de prova cilíndricos de $\phi 100 \mathrm{~mm} \times 200 \mathrm{~mm}$ de comprimento a um ensaio de migração de cloretos com $12 \mathrm{~V}$ de diferença de potencial aplicada. Alguns pesquisadores utilizam fatias de $10 \mathrm{~mm}$ de espessura, o que torna o ensaio mais rápido. Porém, o resultado é altamente influenciado por imprecisões nos cortes das fatias. Desse modo, o uso de fatias finas é recomendado apenas caso o equipamento de corte seja altamente preciso.

A Figura 1 apresenta a configuração do ensaio. A câmara do lado catódico é preenchida com uma solução com $3 \%$ de $\mathrm{NaCl}$ (eletrólito com íon cloreto) e a do lado anódico com água destilada. O volume de cada uma destas câmaras é de 3 litros e, como eletrodos colocados em cada pólo do ensaio, utilizou-se barras de cobre com $35 \mathrm{~cm}$ de comprimento e $6 \mathrm{~mm}$ de diâmetro.

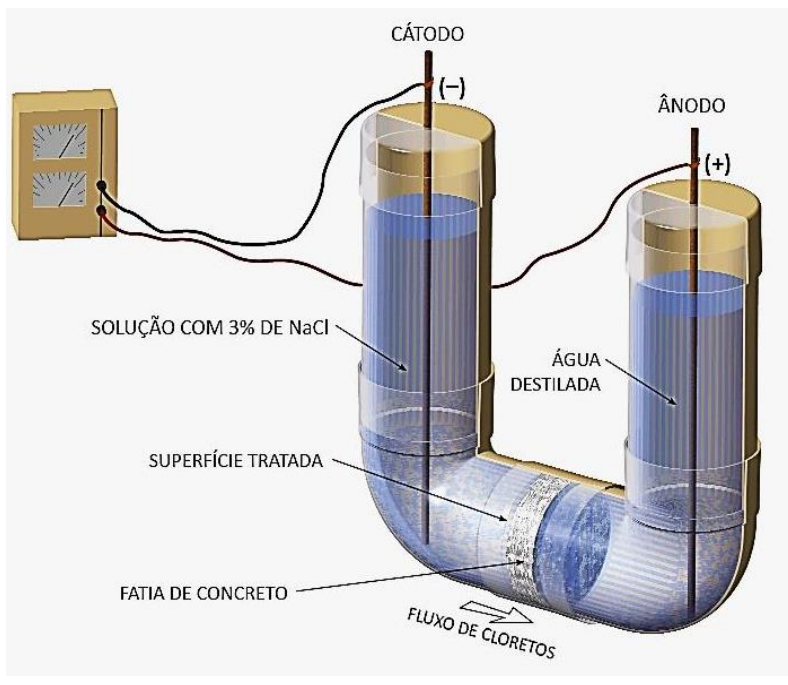

FIGURA 1: Esquema do ensaio de difusão no estado estacionário com voltagem aplicada de $12 \mathrm{~V}$. FONTE: AUTORES (2013).
Como explicado anteriormente, é fundamental que a fatia de concreto esteja totalmente saturada no início do experimento. Ao longo do ensaio, mediu-se a quantidade de cloretos no lado anódico. Isso possibilitou a obtenção do fluxo de cloretos no estado estacionário, o qual é usado para o cálculo do coeficiente de difusão de acordo com a equação de Nernst-Planck (Equação $1)$.

$$
J=\frac{z F}{R T} D C \frac{d E}{d x}
$$

Onde:

$\mathrm{J}=$ fluxo de massa $\left(\mathrm{g} / \mathrm{m}^{2} \mathrm{~s}\right)$;

$\mathrm{D}=$ coeficiente de difusão $\left(\mathrm{m}^{2} / \mathrm{s}\right)$;

$\mathrm{C}=$ concentração $\left(\mathrm{mol} / \mathrm{m}^{3}\right)$;

$\mathrm{dx}=$ distância $(0,025 \mathrm{~m})$;

$\mathrm{z}=$ carga elétrica $($ para cloretos $=-1)$;

$\mathrm{F}=$ constante de Faraday $(96,5 \mathrm{~J} / \mathrm{V} \times \mathrm{mol})$;

$\mathrm{R}=$ constante dos gases $(8,31 \mathrm{~J} / \mathrm{mol} \times \mathrm{K})$;

$\mathrm{T}=$ temperatura $(298 \mathrm{~K})$;

$\mathrm{dE}=$ potencial elétrico $(12 \mathrm{~V})$.

O acompanhamento da concentração de cloretos na câmara anódica foi conduzido pela titulação potenciométrica de amostras extraídas. Estas amostras foram de $5 \mathrm{ml}$ de solução, que foram avolumadas (transformadas em amostras de $50 \mathrm{ml}$ através a adição de água destilada) e a determinação do teor de cloretos foi conduzida nesta solução. Ao final do ensaio, obteve-se o gráfico da concentração de cloretos ao longo do tempo, como ilustra a Figura 2. De acordo com Samson et al. (2003), durante o ensaio, o regime estacionário é atingido quando a concentração de cloretos no ânodo variar linearmente com o tempo, pois isso indica um fluxo constante, que é a definição básica do estado estacionário.

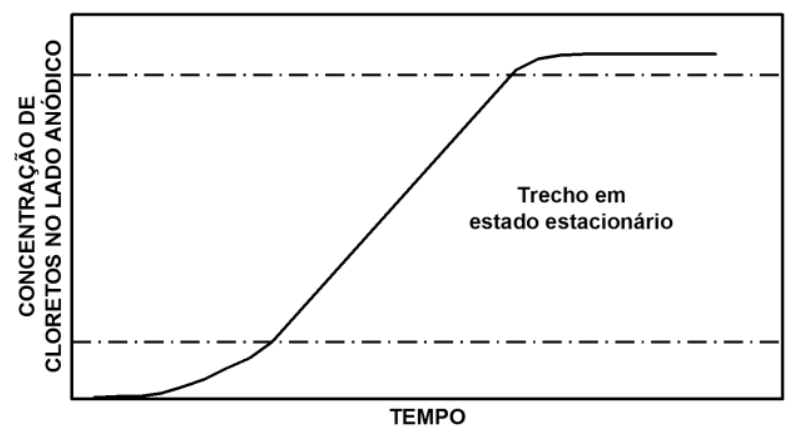

FIGURA 2: Exemplo da variação da concentração de cloretos no lado anódico (pólo positivo). FONTE: AUTORES (2013). 
A partir destes gráficos, o fluxo de cloretos no estado estacionário foi calculado de acordo com a Equação 2. Estes valores foram utilizados na equação de Nernst-Plank (Equação 1) para calcular o coeficiente de difusão de cloretos.

$$
J=\frac{\Delta m_{C l}}{\Delta t A}
$$

Onde:

$\mathrm{J}=$ Fluxo de massa $\left(\mathrm{g} / \mathrm{m}^{2} \mathrm{~s}\right)$;

$\Delta \mathrm{t}=$ Variação do tempo no trecho em estado estacionário (s);

$\Delta \mathrm{mcl}=$ Variação de massa de cloretos no lado anódico no intervalo de tempo $\Delta \mathrm{t}(\mathrm{g})$;

$A=$ Área através da qual os íons cloretos fluem $\left(\mathrm{m}^{2}\right)$.

\section{RESULTADOS E DISCUSSÕES}

A migração de cloretos foi avaliada através do ensaio no estado estacionário e consistiu na variação do teor de cloretos no lado anódico (pólo positivo que foi preenchido com água destilada). As Tabelas 3, 4 e 5 e Figuras 3, 4 e 5 apresentam os valores de coeficientes de difusão de cloretos e taxa de redução determinados usando a primeira lei de Fick da difusão, para os hidrofugantes de superfície, formadores de película e bloqueadores de poros, respectivamente.

Os resultados da Tabela 3 e Figura 3 apresentam que os hidrofugantes de superfície dificultam o transporte dos íons cloretos dentro do concreto e que o uso dos sistemas duplos hidrofugante mais acrílico melhoram ainda mais a capacidade de impedir a penetração de cloretos se comparado com os sistemas simples formados pelo hidrofugante de superfície. Vale salientar que os hidrofugantes de superfície empregados neste estudo apresentaram taxa de redução da penetração de cloretos por difusão de 67 a 92\%.

TABELA 3: Taxa de redução do coeficiente de difusão de cloretos - Hidrofugantes.

\begin{tabular}{c|c} 
Material & Taxa de redução (\%) \\
\hline Referência & - \\
\hline Hidrofugante (A) & 67 \\
\hline Hidrofugante (B) & 84 \\
\hline Hidrofugante (C) & 92 \\
\hline Hidrofugante (A) + acrílico (1)-solv. & 90 \\
\hline Hidrofugante (B) + acrílico (1)-solv. & 95 \\
\hline
\end{tabular}

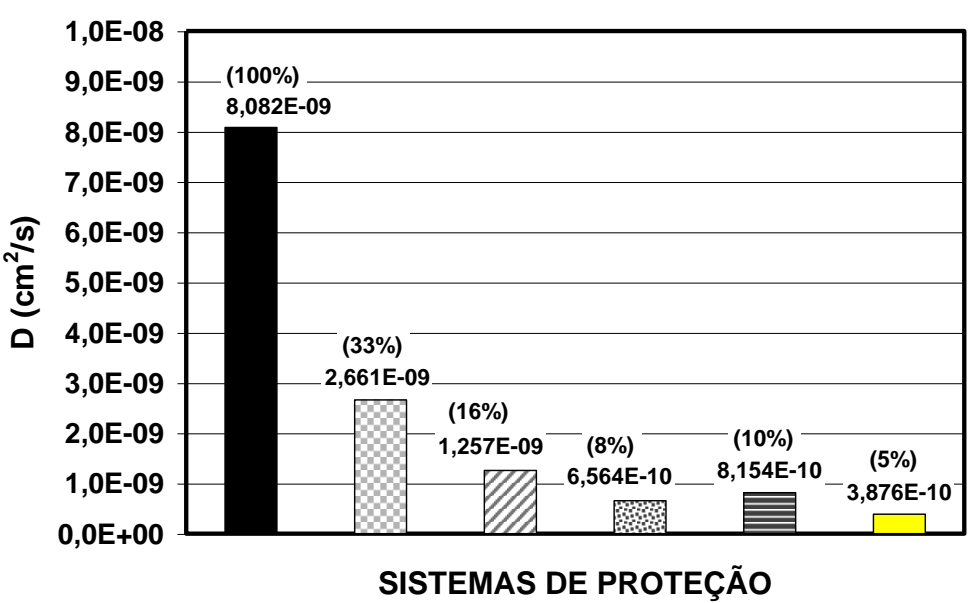

\section{Legenda:}

Referência

$\square$ Hidrofugante (A)

$\square$ Hidrofugante (B)

Hidrofugante (C)

目 Hidrofugante (A) + acrílico (1)-solv.

$\square$ Hidrofugante (B) + acrílico (1)-solv.

FIGURA 3: Coeficiente de difusão de cloretos $\left(\mathrm{cm}^{2} / \mathrm{s}\right)$ para os hidrofugantes de superfície e sistemas duplos. FONTE: AUTORES (2013). 
A Tabela 4 e Figura 4 mostram que os formadores de película a base de poliuretano alifático apresentam maior capacidade de reduzir o coeficiente de difusão de cloretos do substrato a ser protegido se comparados com todos os sistemas simples de proteção utilizados neste estudo.

Entre os formadores de película a base de acrílico, é importante destacar que o produto disperso em água foi o que apresentou a menor capacidade de reduzir a penetração de cloretos no concreto. Vale salientar que, dependendo do formador de película a base de acrílico, sua eficiência pode ser praticamente igual à de um sistema duplo formado por hidrofugante+acrílico. Isso varia com a qualidade dos produtos usados no sistema duplo, indicando que é sempre importante fazer uma análise custo/benefício ao invés de optar por um sistema duplo, sendo que um dado sistema simples poderia resolver o problema de forma satisfatória.

TABELA 4: Taxa de redução do coeficiente de difusão de cloretos - Formadores de película.

\begin{tabular}{c|c} 
Material & Taxa de redução (\%) \\
\hline Referência & - \\
\hline Acrílico (1)-solv. & 83 \\
\hline Acrílico (2)-solv. & 89 \\
\hline Acrílico (3)-água & 63 \\
\hline PU (1) & 95 \\
\hline PU (2) & 94 \\
\hline Hidrofugante (A) + acrílico (1)-solv. & 90 \\
\hline Hidrofugante (B) + acrílico (1)-solv. & 95 \\
\hline
\end{tabular}

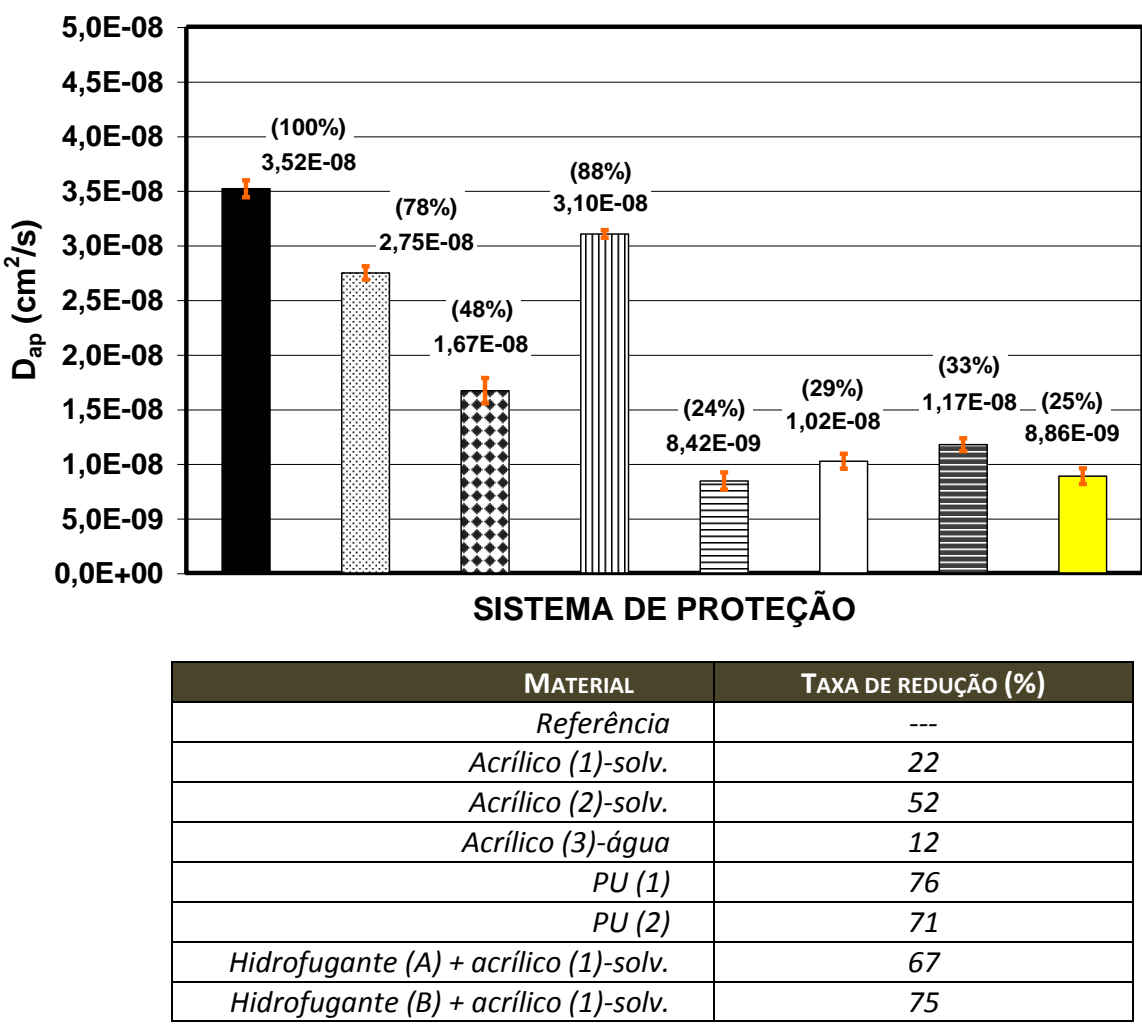

\section{Legenda:}

- Referência

回 Acrílico (1)-solv.

Acrílico (2)-solv.

吕 Acrílico (3)-água

$\boxminus P U(1)$

$\square$ PU (2)

目 Hidrofugante (A) + acrílico (1)-solv. $\square$ Hidrofugante (B) + acrílico (1)-solv.

FIGURA 4: Coeficiente de difusão de cloretos $\left(\mathrm{cm}^{2} / \mathrm{s}\right)$ para os formadores de película e sistemas duplos.

FONTE: AUTORES (2013). 
A Tabela 5 e a Figura 5 mostram mais uma evidência de que os sistemas bloqueadores de poros têm a capacidade de reduzir a porosidade da camada mais superficial do concreto, resultando em uma redução do coeficiente de difusão de cloretos do substrato tratado com este tipo de material. Os resultados indicam que a solução aquosa de silicato de sódio (20\%) apresenta menor capacidade de reduzir o coeficiente de difusão de cloretos do que os demais produtos desta categoria que foram testados neste programa experimental. Este produto teve eficiência da mesma ordem de grandeza do hidrofugante disperso em água [Hidrofugante $(A)$ ].

TABELA 5: Taxa de redução do coeficiente de difusão de cloretos - Bloqueadores de poros.

\begin{tabular}{c|c} 
Material & Taxa de redução (\%) \\
\hline Referência & - \\
\hline Silicato de sódio (20\%) & 64 \\
\hline Produto comercial a base de silicato & 88 \\
\hline Silicato de sódio líquido & 83 \\
\hline
\end{tabular}

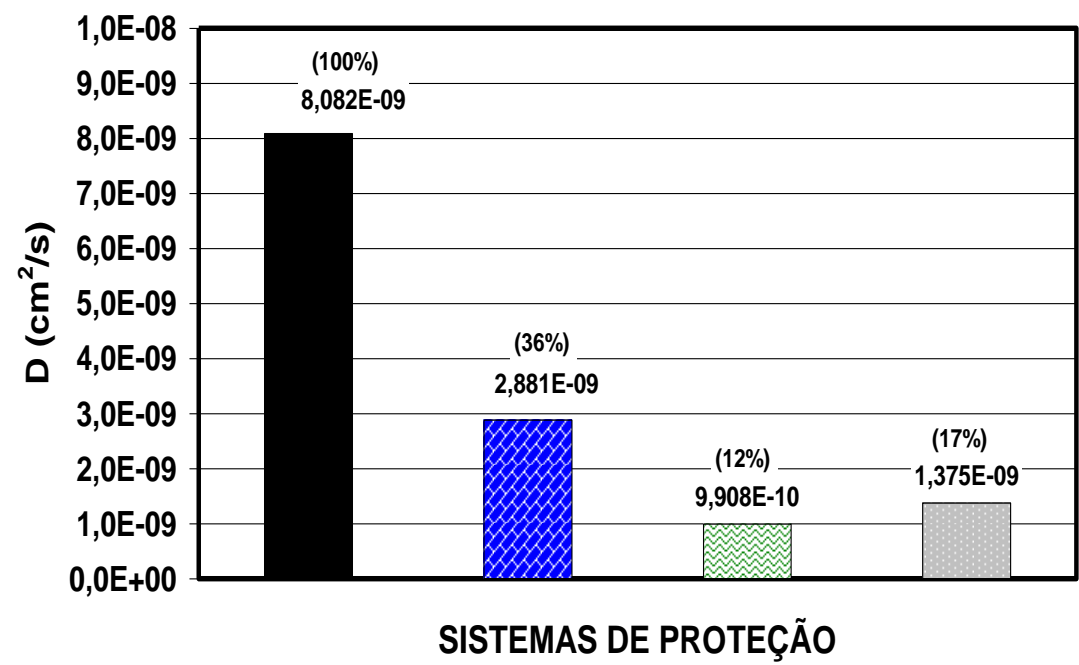

Legenda:

Deferência

$\triangle$ Silicato de sódio (20\%)

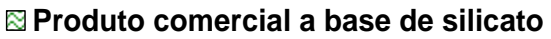

$\square$ Silicato de sódio líquido

FIGURA 5: Coeficiente de difusão de cloretos $\left(\mathrm{cm}^{2} / \mathrm{s}\right)$ para bloqueadores de poros.

FONTE: AUTORES (2013).

Com base nos valores de coeficiente de difusão de cloretos no estado estacionário, pode-se afirmar que os formadores de película a base de poliuretano alifático e os sistemas de dupla proteção formados por hidrofugante (a base de silano/siloxano) associados aos formadores de película (a base de acrílico) são os sistemas de maior poder de redução do coeficiente de difusão de cloretos, entre os produtos estudados neste trabalho, conforme apresentam a Tabela 6 e a Figura 6. 
TABELA 6: Redução do coeficiente de difusão de cloretos (D) de cada categoria de produto testado (estado estacionário).

\begin{tabular}{l|c|c}
\multicolumn{1}{c|}{ Tipo de proteção } & Base do produto & $\begin{array}{c}\text { Percentual de } \\
\text { redução de D }\end{array}$ \\
\hline Hidrofugantes de superfície & Silano/siloxano & $67 \%$ a $92 \%$ \\
\hline \multirow{2}{*}{ Formadores de película } & Acrílico & $63 \%$ a $89 \%$ \\
\hline Bloqueadores de poros & Poliuretano alifático & $94 \%$ a $95 \%$ \\
\hline $\begin{array}{l}\text { Sistema duplo (Hidrofugante + formador de } \\
\text { película) }\end{array}$ & Silicato de sódio & $64 \%$ a 88\% \\
\hline
\end{tabular}

FONTE: AUTORES (2013).

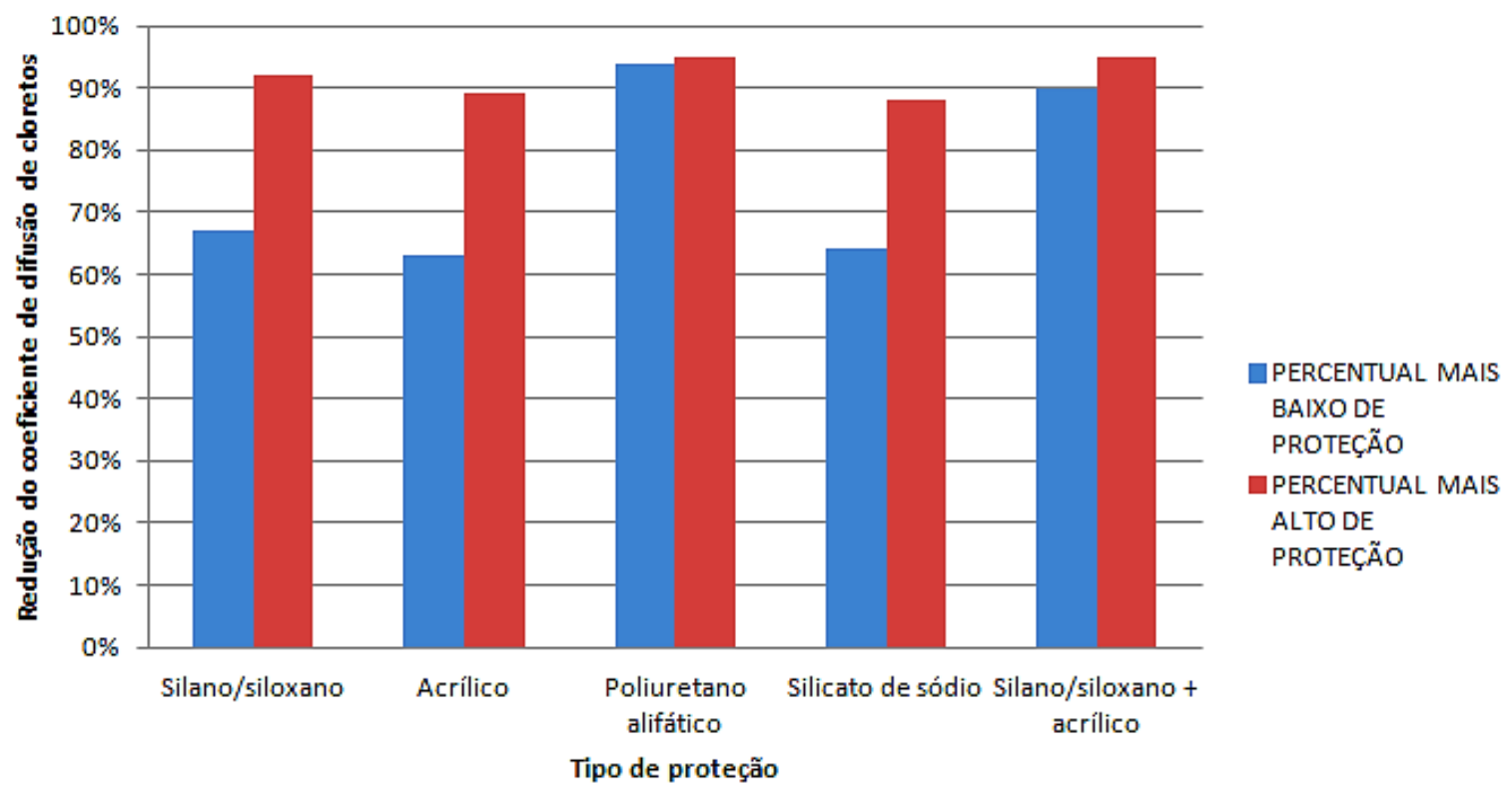

FIGURA 6 - Redução do coeficiente de difusão de cloretos (D) de cada categoria de produto testado. FONTE: AUTORES (2013).

\section{CONSIDERAÇÕES FINAIS}

Para especificar um sistema de proteção de superfície para um determinado caso prático é fundamental conhecer o mecanismo de penetração da umidade ou de cloretos que estará incidindo na estrutura a ser protegida. A água pode penetrar (contaminada com cloretos ou não) por sucção capilar ou por pressão de água. Além disso, no concreto com determinado teor de umidade ou saturado, os íons cloretos podem se transportar por difusão.

As conclusões deste trabalho estão apresentadas a seguir:

Hidrofugantes: Este tipo de proteção indicou elevada capacidade de reduzir a penetração de cloretos nos concretos tratados, mostrando que os hidrofugantes não têm a capacidade apenas de reduzir a penetração de água no concreto como também colaboram para a redução do coeficiente de difusão de cloretos.

Bloqueadores de poros: Os resultados confirmam a capacidade de redução do coeficiente de difusão de cloretos proporcionada pelo tratamento com bloqueadores de poros, indicando que este produto realmente tampona os poros da camada superficial do concreto tratado.

Formadores de película: É importante notar que existem formadores de película a base de acrílico com grande capacidade de reduzir o 
coeficiente de difusão de cloretos, apresentando resultados próximos aos dos sistemas duplos, por exemplo. Em contrapartida, alguns produtos desta natureza podem apresentar baixa capacidade de redução do coeficiente de difusão de cloretos, com resultados semelhantes aos apresentados pelos hidrofugantes de superfície e bloqueadores de poros de menor eficiência. $\mathrm{O}$ poliuretano alifático foi o sistema de proteção que demonstrou a maior eficiência entre os sistemas de camada única testados, apresentando eficiência compatível com o sistema duplo hidrofugante mais acrílico.

\section{REFERÊNCIAS BIBLIOGRÁFICAS}

AMERICAN SOCIETY FOR TESTING AND MATERIALS (ASTM). Standard test method for determining the apparent chloride diffusion coefficient of cementitious mixtures by bulk diffusion. ASTM C-1556. In: Annual book of ASTM Standards. West Conshohocken, 2004.

BATISTA, M. Siloxanos \& silanos. - Perfeitos hidrorrepelentes para toda situação. Revista Recuperar, v. 23, p. 14-19, 1998.

BROMMFIELD, J. P. Corrosion of steel in concrete Understanding, investigation and repair. Londres: $E \& F N$ SPON, 1997.

GUIMARÃES, A. T. da C. Vida útil de estruturas de concreto armado em ambientes marítimos. 2000. 241 p. Tese (Doutorado) - Escola Politécnica, Universidade de São Paulo, São Paulo, 2000.

HELENE P. R. L., TERZIAN P. Manual de Dosagem e Controle do Concreto. São Paulo: PINI, SENAI, 1992. 189 p.

HELENE, P. P Protección y Mantenimiento de las Superfícies de Hormigón. In: CASANOVAS, X. Manual de Diagnosis e Intervención en Estructuras de Hormigón Armado. Espanha: Col-legi d'Aparelladors i Arquitectes Tècnics de Barcelona, Capítulo 12, p. 115-126. 2000.

HELENE, P. R. L. Contribuição ao estudo da corrosão em armaduras de concreto armado. 1993. 231 p. Tese de Livre docência. Escola Politécnica, Universidade de São Paulo (USP), 1993.

HELENE, P. R. L. Manual para reparo, reforço e proteção de estruturas de concreto. São Paulo: FOSROC/PINI, 213 p. 1992.

JACOB, T.; HERMANN, K. Protección de las superficies de concreto: Impregnaciones hidrófobas. Construcción $Y$ Tecnología, p. 18-23, março, 1998.
KROPP, J. Chloride in concrete. In: KROPP, J.; HILSDORF, H. K. Performance Criteria for Concrete Durability. Londres: E \& FN Spon, 1995. Capítulo 6, p. 138-164.

MEDEIROS, M.H.F.; HELENE, P. Surface treatment of reinforced concrete in marine environment: Influence on chloride diffusion coefficient and capillary water absorption. Construction and Building Materials, v. 23, p. 1466-1484, 2009.

MEDEIROS, M.H.F.; HELENE, P. Efficacy of surface hydrophobic agents in reducing water and chloride ion penetration in concrete. Materials and Structures, v. 41, p. 59-71, 2008.

SAMSON, E.; MARCHAND, J.; SNYDER, K. A. Calculation of ionic diffusion coefficients on the basis of migration test results. Materials and Structures, v. 36, p. 156-165, 2003.

THOMPSON, J. L.; SILSBEE, M. R.; GILL, P. M.; SCHEETZ, B. E. Characterization of silicate sealers on concrete. Cement and Concrete Research, v. 27, n. 10, p. 1561-1567, 1997. 